\title{
STRATEGI HUMAS PERUSAHAAN DAERAH AIR MINUM (PDAM) TIRTA KAHURIPAN DALAM PELAYANAN PRIMA KEPADA PELANGGAN
}

\section{PUBLIC RELATIONS STRATEGY PDAM TIRTA KAHURIPAN IN AN EXCELLENT SERVICE TO CUSTOMERS}

\author{
SS Maulida1a, IA Ratnamulyani2a, Agustini ${ }^{3}$ \\ 1,2,3 Jurusan Ilmu Komunikasi, Fakultas Ilmu Sosial dan Ilmu Politik, Universitas \\ Djuanda , Jl. Tol Ciawi No.1 Kotak Pos 35 Bogor 16720. \\ 1a Email Korespondensi: SS Maulida, Email : sixteen.maulida@gmail.com, \\ 2aIA Ratnamulyani, Email : ikea.ratnamulyani@gmail.com
}

(Diterima: 10-5-2017; Ditelaah: 20-6-2017; Disetujui: 28-09-2017)

\begin{abstract}
The strategy is a technique or plans drawn up to achieve the goals and objectives that have previously been determined by a group of people. This research was conducted in PDAM Tirta Kahuripan. The research was conducted in January-July 2016. Analysis of variables in this study used qualitative analysis with in-depth interviews. Once the data is collected in full, the next step is to analyze the data. Data analysis techniques with three stages, the first data reduction, the second presentation of the data in the form of narrative text, the third conclusion. The research results showed a public relations strategy that was done by the service with enhance corporate image and provide services in order to convince the customer.
\end{abstract}

Keywords: strategy, public relations, excellent service, corporate image

\begin{abstract}
ABSTRAK
Strategi adalah teknik atau rencana yang disusun untuk mencapai sasaran dan tujuan yang sebelumnya telah ditentukan oleh sekelompok orang. Penelitian ini dilakukan di PDAM Tirta Kahuripan. Waktu penelitian dilakukan pada bulan Januari-Juli 2016. Analisa Variabel dalam penelitian ini digunakan analisa kualitatif yaitu dengan wawancara mendalam. Setelah data terkumpul dengan lengkap, langkah selanjutnya adalah menganalisis data. Teknik analisis data dengan 3 tahapan, pertama reduksi data, kedua penyajian data berupa teks naratif, ketiga penarikan kesimpulan. Adapun hasil penelitian menunjukkan startegi humas yang dilakukan dengan pelayanan prima dapat meningkatkan citra perusahaan dan memberikan pelayanan guna meyakinkan pelanggan.
\end{abstract}

Kata Kunci: strategi, humas, pelayanan prima, citra perusahaan.

SS Maulida, IA Ratnamulyani, Agustini. 2016. Strategi Humas PDAM Tirta Kahuripan dalam pelayanan prima kepada pelanggan. 3(1):69-74. 


\section{PENDAHULUAN}

Kebutuhan akan air bersih semakin lama semakin meningkat tetapi persediaan sumber daya alam berupa air bersih dan sehat mulai berkurang di beberapa Kabupaten, seperti wilayah Ciomas. Air yang bersih dan sehat diperlukan untuk mendukung segala aktivitas manusia setiap harinya karena air memegang peranan penting sebagai kebutuhan keluarga, irigasi, rekreasi, dan industri. Hal ini yang membuat masyarakat berminat untuk menggunakan jasa penyedia air bersih, sehat, dan layak dikonsumsi yang dikelola salah satu penyelenggara perusahaan pengelola air bersih dan sehat di wilayah Ciomas Kabupaten Bogor.

Bentuk pelayanan yang diberikan oleh PDAM Tirta Kahuripan Cabang VI Ciomas kepada pelanggan air bersih dan sehat diantaranya reparasi pipa pelanggan yang bocor, menerima pengaduan pelanggan melalui layanan pengaduan dengan menghubungi nomor telepon yang tersedia, dan pelayanan secara langsung dengan datang ke loket kantor PDAM Titra Kahuripan Cabang VI Ciomas Bogor. Semakin meningkat jumlah pelanggan maka PDAM di tuntut untuk mempunyai kemampuan yang tinggi dalam memberikan pelayanan kepada pelanggan dan terus meningkatkan pelayanan yang baik dan berkualitas.

Kepala Divisi Humas PDAM Tirta Kahuripan Cabang VI Bapak Ali R, SE mengatakan PDAM Tirta Kahuripan Cabang VI Ciomas telah berupaya memberikan pelayanan terbaik dalam memenuhi kebutuhan air bersih. Namun nyatanya masih terdapat masalah seperti kebutuhan air semakin meningkat tetapi tidak dapat diseimbangkan dengan persediaan sumber daya air bersih dan sehat di wilayah ciomas. Pelanggan PDAM Tirta Kahuripan Cabang VI Ciomas sering menyatakan air yang keruh, tidak mengalir, dan meteran rusak atau mati. Selain itu petugas humas memberikan pengertian yang salah mengenai alat-alat dari PDAM Tirta
Kahuripan Cabang VI Ciomas seperti water mater, stop kran, pipa persil, kran air, dan pipa jawatan dan apa fungsinya kepada pelanggan, sehingga dalam memberikan informasi dan pelayanan kepada pelanggan belum optimal.

Pihak PDAM bagian humas melaksanakan pengawasan dalam menangani keluhan pelanggan yakni dengan turun kelapangan secara langsung untuk melihat keadaan yang sebenarnya dilapangan sesuai dengan keluhan yang disampaikan yaitu air yang tidak mengalir. Maka pelanggan bisa menyampaikan secara langsung keluhan mereka terhadap kualitas air yang kurang baik.

Berdasarkan pernyataan diatas masalah yang ditemukan dalam penelitian yaitu: Bagaimana Strategi Humas PDAM Tirta Kahuripan Cabang VI dalam pelayanan prima air bersih dan sehat kepada pelanggan wilayah Ciomas Bogor?

\section{METODE PENELITIAN}

Metode penelitian yang digunakan deskriptif kualitatif, yakni sebuah desain yang memberi kemudahan bagi peneliti untuk merekam, memantau dan mengikuti proses suatu peristiwa atau kegiatan sebuah organisasi sebagaimana adanya dalam suatu kurun waktu tertentu dan selanjutnya diinterprestasikan untuk menjawab masalah penelitian (Sugiyono 2013).

Penelitian mengenai strategi humas perusahaan daerah air minum (PDAM) tirta kahuripan cabang VI dalam pelayanan prima air bersih dan sehat kepada pelanggan wilayah Ciomas Bogor, subjek penelitian terdiri dari informan yang bernama Bapak A. R, SE. sebagai Kepala Seksi Humas, informan kedua yaitu Bapak Deni S, jabatan nya sebagai Staf Humas, selanjutnya Bapak Kw jabatannya sebagai Staf Humas, kemudian Bapak E. S, beliau juga menjabat sebagai Staf Humas di PDAM Tirta Kahuripan Cabang VI Ciomas, dan Kepala Bagian Langganan yaitu Bapak H. Ka. Subjek penelitian ini yang akan diambil 
data dan keterangan maupun informasi untuk keperluan penelitian. Data penelitian dikumpulkan berdasarkan data primer dan data sekunder. Pengumpulan data primer dilakukan melalui wawancara mendalam (idepth interview) dan observasi lapangan. Sedangkan data sekunder dikumpulkan dari studi kepustakaan dan dokumentasi. Data penelitian dianalisis dengan analisis melalui tiga tahapan pertama, reduksi data. kedua, penyajian data. ketiga, penarikan kesimpulam. Validitas data pada penelitian ini menggunakan triangulasi. Menurut Moleong, (2004) teknik triangulasi yang digunakan adalah teknik triangulasi sumber dan motode.

\section{HASIL DAN PEMBAHASAN}

\section{Strategi Humas}

Perencanaan strategi Humas yang dilakukan oleh Humas Perusahaan Daerah Air Minum (PDAM) Tirta Kahuripan Ciomas antara lain adalah mengadakan kunjungan langsung pihak perusahaan seperti Kepala Cabang beserta jajarannya ke lokasi warga sehingga pihak perusahaan dapat berdialog dan berinteraksi dengan warga yang berkaitan dengan jasa air bersih dan sehat, seperti masalah pelayanan yang diberikan oleh Perusahaan Daerah Air Minum (PDAM) Tirta Kahuripan Cabang VI terhadap warga di wilayah Ciomas Kab.Bogor sehingga PDAM Ciomas dapat mengambil langkah penyelesaian secara tepat.

Perencanaan yang dilakukan yaitu mengadakan acara temu pelanggan dengan pengguna jasa air bersih dan sehat di wilayah ciomas secara rutin.

Pesan yang disampaikan Humas Perusahaan Daerah Air Minum (PDAM) Tirta Kahuripan Cabang VI Ciomas adalah "Perusahaan Daerah Air Minum (PDAM) Ciomas berusaha memberikan pelayanan yang optimal terhadap pelanggannya". Pesan tersebut memiliki makna dan daya tarik yaitu, bahwa PDAM Tirta Kahuripan Cabang VI Ciomas selalu berusaha memberikan pelayanan prima terhadap pelanggannya sehingga pelanggannya merasa puas atas pelayanan yang diberikan.

Dari rasa puas pelanggan tersebut, dapat menimbulkan hubungan baik antara pelanggan dengan Perusahaan Daerah Air Minum (PDAM) Tirta Kahuripan Cabang VI Ciomas, sehingga akan adanya kepercayaan pelanggan terhadap pihak PDAM Tirta Kahuripan Cabang VI Ciomas.

Media yang digunakan dalam memberikan pelayanan prima kepada pelanggannya yaitu menggunakan media brosur, media massa melalui programprogramnya.

Keberhasilan dalam mengembangkan dan melaksanakan layanan prima tidak lepas dari kemampuan dalam pemilihan konsep pendekatannya. Konsep pelayanan prima PDAM Tirta Kahuripan Cabang VI Ciomas berdasarkan karakteristiknya ada enam, Ruslan (2005) yaitu : Kemampuan (ability), Sikap (attitude), Penampilan (appearance), Perhatian (attention), Tindakan (action), dan Tanggungjawab (accountability).

Kemampuan (ability) adalah pengetahuan dan keterampilan tertentu yang mutlak diperlukan untuk menunjang program pelayanan prima.

Sikap (Attitude) adalah perilaku atau perangai yang harus ditonjolkan ketika menghadapi pelanggan, yang meliputi penampilan yang sopan dan serasi, berfikir positif, sehat, logis dan bersikap menghargai.

Penampilan (Apperance) adalah penampilan seseorang baik yang bersifat fisik saja maupun non fisik, mampu merefleksikan kepercayaan diri dan kredibilitas dari pihak lain.

Perhatian (Attention) adalah kepedulian penuh kepada pelanggan, baik yang berkaitan dengan perhatian akan kebutuhan dan keinginan pelanggan maupun pemahaman atas saran dan kritiknya. 
Tindakan (Action) adalah berbagai kegiatan nyata yang harus dilakukan dalam memberikan layanan kepada pelanggan.

\section{Tanggungjawab (Accountability)} adalah suatu sikap keberpihakan kepada pelanggan sebagai suatu wujud kepedulian untuk menghindarkan atau meminimalkan kerugian atau ketidakpuasan pelanggan.

Dengan adanya keenam konsep pelayanan prima PDAM Tirta Kahuripan Cabang VI Ciomas akan menuai citra yang positif dan pelanggan merasa puas terhadap pelayanan yang diberikan dengan optimal. Pelayanan di PDAM Tirta Kahuripan Cabang VI Ciomas meliputi: Prosedur pelayanan merupakan salah satu dari standar pelayanan pelanggan. Kedua, Waktu penyelesaian yang di tetapkan oleh PDAM Tirta Kahuripan saat pengajuan permohonan sampai dengan penyelesaian pelayanan termasuk saat menangani pengaduan dari pelanggan. Pelayanan publik di PDAM Tirta Kahuripan yang ketiga yaitu Produk pelayanan merupakan salah satu dari standar pelayanan public. Pelayanan di PDAM Tirta Kahuripan yang Keempat adalah, Biaya Pelayanan termasuk rinciannya harus ditentukan secara konsisten dan tidak boleh ada kesalahan, sebab akan menimbulkan ketidakpercayaan penerima pelayanan/pelanggan.

Untuk dapat memberikan kepuasan bagi pelanggannya, maka perusahaan yang bergerak dibidang jasa haruslah memahami kualitas pelayanan sehingga akan memberikan suatu kerangka kerja tentang apa yang akan dijadikan pilihan atau alternatif oleh pengguna jasa didalam menilai kualitas pelayanan dari penyediaan jasa tersebut. Kualitas Pelayanan dapat diketahui dengan cara membandingkan persepsi para konsumen atas pelayanan yang nyata-nyata mereka peroleh dengan pelayanan yang sesungguhnya mereka harapkan.

Pelayanan yang diberikan oleh aparatur PDAM Tirta Kahuripan Cabang VI Ciomas dalam menangani pengaduan pelanggan sejauh ini masih cukup baik dalam menangani pengaduan keluhan pelanggan yang dilakukan baik secara langsung berhadapan dengan pelanggan atau melalui website dan media komunikasi lainnya.

Perencanaan yang akan dilakukan oleh Humas Perusahaan Daerah Air Minum (PDAM) Tirta Kahuripan Cabang VI Ciomas yaitu mengadakan pertemuan-pertemuan dengan para pelanggan atau kunjungan langsung Ka. Cabang beserta staf sehingga terjadi interaksi dan dialog-dialog. Dari interaksi dan dialog-dialog tersebut perusahaan dapat mengetahui permasalahan yang dihadapi oleh pelanggan, sehingga perusahaan dapat mengambil tindakan untuk menyelesaikan permasalahan tersebut secara tepat.

Pesan atau informasi yang disampaikan oleh humas PDAM Tirta Kahuripan Cabang VI Ciomas kepada pelanggannya harus sesuai dengan misi PDAM Ciomas, pesan yang disampaikan harus dapat menimbulkan pengertian dan perhatian, pesan tersebut dikemas sedemikian rupa hingga mempunyai daya tarik yang membuat pelanggan ingin mengetahui, membaca dan memahami. Sehingga pesan yang disampaikan dapat diterima baik oleh pelanggan, dan tidak menimbulkan salah pengertian antara perusahaan dengan pelanggan.

\section{Objek Pesan}

Pesan yang disampaikan oleh Humas Perusahaan Daerah Air Minum (PDAM) Tirta Kahuripan Cabang VI Ciomas, yaitu : "Akan Terus Berupaya Meningkatkan Pelayanan Kepada Pelanggan". Humas Perusahaan Daerah Air Minum (PDAM) Tirta Kahuripan Cabang VI Ciomas menggunakan media brosur dan media massa dalam menyampaikan informasi yang terkait tentang PDAM Tirta Kahuripan Cabang VI ciomas, karena dianggap efektif dalam menyampaikan informasi kepada pelanggannya.

Hal ini evaluasi yang dilakukan oleh Humas Perusahaan Daerah Air Minum (PDAM) Tirta Kahuripan Cabang VI Ciomas, 
yaitu : menilai keberhasilan rencana, tujuan dan kegiatan, pesan dan media yang digunakan dalam pelayanan prima kebutuhan air bersih dan sehat kepada pelanggan wilayah ciomas bogor dan hasil yang ingin dicapai oleh Humas Perusahaan Daerah Air Minum (PDAM) Ciomas dari semua rangkaian rencana, tujuan dan kegiatan yang dilakukan yaitu citra dan pandangan yang baik dimata pelanggan Perusahaan Daerah Air Minum (PDAM) Ciomas sehingga dapat meningkatkan kinerja atau pelayanan Perusahaan Daerah Air Minum (PDAM) Ciomas, selain itu juga pelanggan dapat memahami permasalahan yang dihadapi oleh Perusahaan Daerah Air Minum (PDAM).

\section{Strategi Humas Perusahaan Daerah Air Minum (PDAM) Tirta Kahuripan Cabang VI dalam Pelayanan prima Kebutuhan Air Bersih dan Sehat di wilayah Ciomas Bogor}

Strategi Humas Perusahaan Daerah Air Minum (PDAM) dalam pelayanan prima air bersih dan sehat kepada pelanggan sebagai perencana dan penanggung jawab selain memberikan pelayanan prima, Humas Perusahaan Daerah Air Minum (PDAM) Tirta Kahuripan Cabang VI Ciomas juga berusaha mewujudkan misi perusahaan yaitu Memberikan pelayanan dengan kualitas air sesuai dengan persyaratannya yang berlaku dan kuantitas yang memadai secara kontinyu, Membina dan menjalin hubungan baik dengan pelanggan dan stakeholder perusahaan, Meningkatkan kinerja keuangan perusahaan, Mengutamakan pengembangan pada segmen rumah tangga dengan tetap memperhatikan segmen non rumah tangga. Humas PDAM Tirta Kahuripan Cabang VI Ciomas telah berperan baik dalam meningkatkan citra perusahaan dengan memberikan pelayanan optimal kepada pelanggan karena perencanaan yang telah di tetapkan tersebut berjalan dengan baik. Pesan yang disampaikan dapat dimengerti oleh pelanggan dan media yang digunakan pun dapat menyampaikan langsung kepada pelanggannya.

Humas PDAM telah menentukan strategi apa saja yang akan di jalankan dalam pelayanan prima kebutuhan air bersih dan sehat kepada pelanggan wilayah ciomas yaitu Pertama Perencanaan Divisi Humas dalam berkunjung ke lokasi warga untuk berinteraksi langsung dengan pelanggan PDAM Tirta Kahuripan Cabang VI Ciomas, Kedua menyusun pesan yaitu pesan yang disampaikan oleh Humas Perusahaan Daerah Air Minum (PDAM) yakni "Perusahaan Daerah Air Minum (PDAM) Tirta Kahuripan Cabang VI Ciomas berusaha memberikan pelayanan yang optimal terhadap pelanggannya". Diharapkan pesan tersebut dapat menimbulkan perhatian dan pengertian di pihak pelanggannya, dan pelanggan dapat mengetahui bahwa PDAM Tirta Kahuripan Cabang VI berusaha memberikan pelayanan yang optimal. Ketiga, Menggunakan media brosur, selain menggunakan media tersebut Humas PDAM Tirta Kahuripan menggunakan media massa, media tersebut dianggap efektif dan mempunyai pengaruh yang cukup besar dalam menyebarkan informasi yang berkaitan dengan perusahaan, seperti program-program yang akan diadakan, tentang pelayanan air bersih dan sehat terhadap pelanggan. Dan strategi humas Keempat Evaluasi, yaitu hasil yang ingin dicapai oleh PDAM Tirta Kahuripan Cabang VI Ciomas dari semua rangkaian rencana, tujuan dan kegiatan yag dilakukan yaitu citra dan pandangan yang baik dimata pelanggan Perusahaan Daerah Air Minum (PDAM) sehingga dapat meningkatkan kinerja atau pelayanan PDAM, selain itu juga pelanggan dapat memahami permasalahan yang dihadapi oleh perusahaan Daerah Air Minum (PDAM) Tirta Kahuripan Cabang VI Ciomas. 


\section{KESIMPULAN DAN IMPLEMENTASI}

Sugiyono. 2013. Metode Penelitian Administrasi. Bandung (ID): Alfabeta

\section{Kesimpulan}

1. Strategi Humas yang dilakukan Humas PDAM Ciomas dapat memberikan pelayanan prima, dalam kebutuhan air bersih dan sehat kepada pelanggan, sehingga dapat meningkatkan citra perusahaan.

2. Strategi Humas dilakukan dalam memberikan pelayanan untuk meyakinkan kepada pelanggan bahwa, PDAM Tirta Kahuripan Cabang VI Ciomas sebagai penyedia kebutuhan air bersih dan sehat terus mengembangkan pelayanan ke arah yang lebih baik.

3. Pelayanan prima yang diberikan secara optimal kepada pelanggan menuai citra positif dan pelanggan merasa puas terhadap pelayanan PDAM Tirta Kahuripan Cabang VI Ciomas dalam kebutuhan air bersih dan sehat.

\section{Implementasi}

1. Sebaiknya PDAM Tirta Kahuripan Cabang VI Ciomas menambah dan memiliki media komunikasi yang lebih mudah melalui teknologi website, media social, aplikasi mobile dan teknologi lainnya. Untuk memudahkan pelanggan dalam mencari dan mendapatkan informasi dari PDAM Tirta Kahuripan Cabang VI Ciomas.

2. PDAM sebagai perusahaan penyedia air minum harus membuat inovasi produknya di masa yang akan datang, salah satu contohnya adalah air bersih yang dapat langsung dikonsumsi masyarakat.

\section{DAFTAR PUSTAKA}

Moleong LJ 2002. Metode Penelitian Kualitatif. Bandung (ID) : Remaja Rosda Karya.

Ruslan R. 2005. Kiat dan Strategi Kampanye Public Relations. Jakarta (ID): PT. Rajagrafindo Persada. 